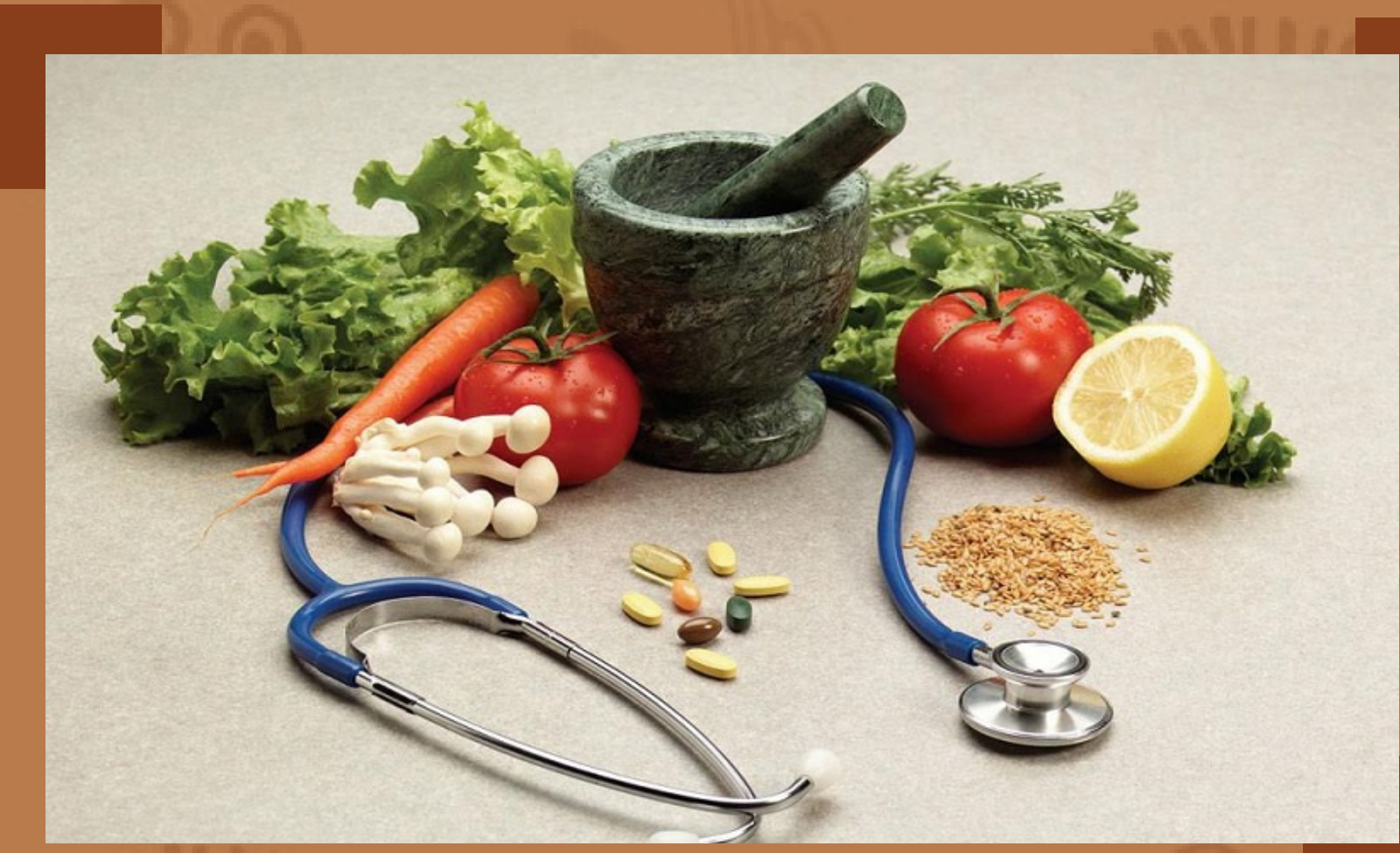

\title{
Sentir, expresar y padecer: Reflexiones desde la Antropología de la Salud
}

Antropologia de la Salud 


\section{Sentir, Expresar y Padecer: Reflexiones desde la Antropología de la Salud}

\section{Feel, Express and Suffer: Reflections from the Anthropology of Health}

Luis Carlos Ariel Ruiz Chow

Antropólogo Social en la Universidad Nacional Autónoma de Nicaragua

UNAN-Managua.

ID Orcid: https://orcid.org/0000-0001-5855-8187

luis.ruchw@gmail.com

\section{Resumen}

La antropología de la salud, es la disciplina que se encarga de comprender las expresiones y narrativas que componen el sentir, padecer y expresar, sobre los síntomas patológicos, y como estos se explican desde la cosmovisión de un determinado contexto, al igual que sus métodos e instrumentos para curar y prevenir la enfermedad. Es a partir de tales inquietudes que parto hacia la sistematización y compilación de investigaciones que tienen como centro de referencia la antropología, trascendiendo al campo de la salud mental, desde la piscología, psiquiatría y sociología, aglomerando y tensionando sobre las posturas y reflexiones generadas por los autores. Es en esta tensión, que se sitúa el sentir y expresar, como dos ejes medulares para comprender la enfermedad mental, entendiendo que el padecimiento tiene varianzas y matices distintos, según las instituciones, entramados culturales, semióticas y dinámicas lingüísticas, donde el enfermo se encuentre inmerso.

Palabras claves: Antropología de la salud, Salud, Enfermedad, Malestar, Narrativas, Etno-psicología.

\section{Abstract}

Health anthropology is the discipline that is responsible for understanding the expressions and narratives that make up feeling, suffering and expressing, about pathological symptoms, and how these are explained from the worldview of a certain context, as well as its methods and instruments to cure and prevent disease. It is from such concerns that I start towards the systematization and compilation of research that has anthropology as a reference center, transcending the field of mental health, from psychology, psychiatry and sociology, agglomerating and stressing on the positions and reflections generated by the authors. It is in this tension that feeling and expressing are situated, as two core axes to understand mental illness, understanding that the condition has variances and different nuances, according to the institutions, cultural, semiotic and linguistic dynamics, where the patient is immersed.

Keywords: Anthropology of health, Health, Illness, Discomfort, Narratives, Ethno-psychology. 


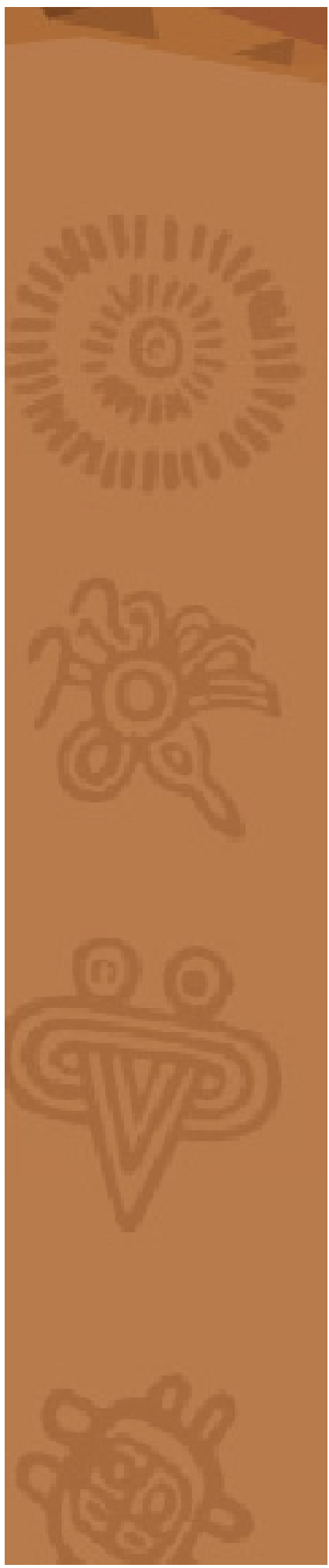

\section{Introducción}

La antropología es una ciencia integral, de amplias dimensiones y preocupaciones sociales. Dentro de esas preocupaciones se encuentra el complejo campo de la salud y la enfermedad; por tanto, la antropología de la salud, es la disciplina que se encarga de comprender las expresiones y narrativas que componen el sentir, padecer y expresar los síntomas patológicos y como estos se explican desde la cosmovisión de un determinado contexto, al igual que sus métodos e instrumentos para curar y prevenir la enfermedad.

Planteado esto, el estado de arte presente, tiene como objetivo el sistematizar aportes importantes desde la etno-psicología, etno-psiquiatría y la antropología de la salud sobre algunas enfermedades mentales, desde un enfoque transcultural, de manera que, se utilice como precedente ante posibles investigaciones futuras que pretendan analizar el padecimiento, malestar y sintomatologías desde la ciencia antropológica.

\section{Material y métodos}

El presente documento, se fundamenta en la revisión documental, para la sistematización de la información y trabajos investigativos realizados, con el fin de presentar los hallazgos y antecedentes científicos más relevantes, desde el campo de la psicología, psiquiatría y sociología, con enfoque antropológico.

\section{Antecedentes de la Antropología de la Salud (Mental)}

Un equipo de investigadores multidisciplinares (psicólogos, sociólogos y antropólogos) peruanos, se dieron a la tarea de analizar la depresión en 2006, desde un enfoque transcultural. Para esto, retomaron los aportes de otros investigadores en la materia, entre ellos los psiquiatras, Byron Good y Arthur Kleinman, pioneros en las investigaciones de la salud mental, específicamente la depresión, respecto a la cosmovisión de distintas culturas en Asia y África.

Según los investigadores "cada sociedad elabora sus propios modelos de expresión psicopatológica (...) es decir, que el sentir y la manifestación del síntoma varian significativamente de una cultura a otra" (Villaseñor, Rojas, Albarrán, \& Gonzáles, 2006, pág. 43) Es correcto afirmar que, el sentir y expresar síntomas depresivos varía entre culturas, y cada una de ellas desarrolla síntomas distintos e incluso formas para comunicar el padecimiento, al igual que instrumentos de curación distintas entre sí.

Los autores hacen énfasis en el planteamiento de la psiquiatra y psicoterapeuta, Evelyne Pewzner-Apeloig (1999, pág. 14), quien indica que el enfermo dispone de maneras de expresar su malestar a partir de los comportamientos sociales propios de su cultura, siendo "términos específicos de los que dispone el enfermo para expresar-su malestar-" (Pewzner-Apeloig, 1999, pág. 14)

Por ejemplo, Kleinman (2003, págs. 120-125) describe las manifestaciones de la depresión según distintas culturas y contextos geográficos: 
- Los pacientes chinos principalmente manifiestan aburrimiento, fatiga, molestias presión interna, dolor y mareo, sin embargo, los pacientes "encuentran el diagnostico de depresión moralmente inaceptable y además una expresión sin sentido" (Villaseñor, Rojas, Albarrán, \& Gonzáles, 2006, pág. 45) esto debido a que disminuye su actividad laboral y recae en el ocio, una categoría más alarmante que la depresión en sí.

- Las mujeres en Dubái manifiestan principalmente síntomas físicos, puesto que "es más aceptada la manifestación somática que la emocional (...) debido a que deben aguardar silencio acerca de sus dificultades psicológicas para no perjudicar la reputación familiar" (Villaseñor, Rojas, Albarrán, \& Gonzáles, 2006, pág. 45).

- En Tailandia los síntomas son somáticos y están ligados a los sentimientos de culpa, presentando cuadros como tristeza, ansiedad, pérdida de interés y baja autoestima.

- En países del Nor-este africano, en los tres dialectos del Magreb no hay palabra alguna para expresar de forma directa el estado depresivo, "la depresión se presenta de forma enmascarada en forma de quejas somáticas o de estados delirantes con síntomas como astenia, anorexia y abulia" (Villaseñor, Rojas, Albarrán, \& Gonzáles, 2006, pág. 47)

- Los latinoamericanos son "propensos a somatizar afecciones acompañados de modismos culturales que suelen confundir el diagnostico (...) sin embargo, suelen no hacer distinción entre las emociones de ansiedad, irritabilidad y depresión" (Villaseñor, Rojas, Albarrán, \& Gonzáles, 2006, pág. 47)

\section{Los padeceres, sentires y sus expresiones en Latinoamérica}

Sobre este último contexto es que aterrizaremos el análisis, ya que entre la cultura Náhuatl e Inca hay correlación entre la expresión de la depresión como una modalidad construida por distintas acontecimientos socio-históricos, incluso políticos como es el susto o espanto, sin embargo ambas culturas tienen detonantes y padeceres distintos.

La etiología del susto (caso Náhuatl) no es la pérdida del ánimo como señala el IC10, sino la pérdida de una entidad anímica localizada en la cabeza que se denomina tonalli, que es una palabra derivada del verbo tona que significa irradiar, calor solar, espíritu. Dicha pérdida generalmente se asocia a miedo e impresiones fuertes, causando síntomas como pérdida del vigor, palidez, fiebre, hiperoxia, hipersomnia y pérdida del brillo en la mirada. Se considera que esta enfermedad es provocada por los aires, representaciones de entidades sobrenaturales de origen pre-colombino (Villaseñor, Rojas, Albarrán, \& Gonzáles, 2006, pág. 48)

Este síndrome se encuentra presente en la cultura Aymara-quechuas, y se manifiesta por medio de síntomas somáticos, conocido como "manchariska (...) causado por la salida del alma de sus confines corporales (ajayu) acompañados pos síntomas como náuseas, cefaleas, vómitos, delirios y alucinaciones" (Villaseñor B. S., 2005, pág. 122) 
Mario Gabriel Hollweg (2003, págs. 6-14) médico psiquiatra, detalla en su artículo: Trastornos afectivos en las culturas bolivianas. Un enfoque etno-psiquiátrico transcultural una serie de afecciones según la región andina y el detonante de la depresión:

Síndromes afectivos de origen mítico:

"Relacionado con conceptos animísticos y dualísticos de la interrelación ánima-cuerpo, la cual puede ser afectada por situaciones determinadas y se manifiesta por medio de trastorno corporales" (Hollweg, 2003, pág. 7) Esta somatización muta en uno de los siguientes síndromes afectivos: susto, colerina y pena.

Según Hollweg (2003, pág. 7) asegura que el susto es una de las enfermedades míticas más antiguas y difundidas en el mundo andino, la cual parte como creencia del secuestro del alma por espíritus malignos, presentando síntomas como: pérdida del ánimo, ansiedad, quejas y malestares, delirios, alucinaciones y confusión.

La colerina son comportamientos de intensa reacción emocional de rabia ocasionada por disgustos, presentan síntomas como: trastornos anímicos, perturbaciones en las funciones hapatobiliares y digestivas, vómitos biliosos y cólicos.

Por último, la pena, es "el mal generalizado del alma andina" (Hollweg, 2003, pág. 8) y su sintomatología es distinta según la región andina. Estos se clasifican de la siguiente manera:

1) Amartelo: provocado en los hijos por el abandono de los padres o amores frustrados (no correspondidos)

2) Songo nanay purishan: pesadumbre profunda y contagiosa, acompañado de ideas suicidas.

\section{3) Phustisga: ocasionado por desastres económicos}

4) Kashgo nanay y pecho nanay: se relacionan con frustraciones amorosas o sentimentales, presentan dolor de pecho, falta de aires, se descuidan del trabajo y la apariencia personal.

Síndromes afectivos de influencia hispánica: depresión de tipo melancólica y la tiricia, o cambios de estado afectivo caracterizados por fluctuaciones entre la pérdida del ánimo, ansiedad, agresividad y tristeza.

Síndromes afectivos de transición: la correlación entre los síndromes del susto/ depresión, colerina/congestión, y la forma de expresión es indeterminada al ser síntomas explicados por términos españoles desde el lenguaje quechua o viceversa.

Síndromes por desarraigamientos: debido a migraciones forzadas, siendo obligados a trabajar en regiones inhóspitas. Presentan síntomas psicóticos, alteraciones de estados de conciencia, delirios, trastornos psicomotores y anorexia. Cambios de humor, y malestar estomacal se presentan en niños durante el destete. 
Cuando se refieren a delirios o alucinaciones, se refieren a cuadros de reacción psicótica, los cuales comprenden, síntomas oscilatorios "de la conciencia y de los impulsos: estupor, excitación psicomotora, desorientación, perplejidad, estados de trance, confusión, ideas delirantes relacionadas entre la dualidad mítica-cristiana, insomnio, anorexia, fluctuación entre tristeza y euforia o expansividad" (Hollweg, 2003, pág. 18)

En Nicaragua se han registrado dos tipos de Síndromes Culturales Propios: Grisi Siknis y El Bla.

En el Mapa de la Salud Mental, del Ministerio del Poder Ciudadano para la Salud de Nicaragua (MINSA, 2017, pág. 1) se contempla:

Grisi siknis o Krisi siknis (Miskitus nicaragüenses y honduras): denominado locura de la selva, afecta en su mayoría a mujeres jóvenes. Presenta los siguientes cuadros como: ansiedad, náuseas, malestar, furia irracional, miedo, estados de alucinación y frenesí temporal. Generalmente el arquetipo psicótico corresponde al ataque sexual de un diablo.

El psiquiatra, Ronald C. Simons y el antropólogo, Charles C. Hughes (1985); realizaron una compilación titulada: Los síndromes ligados a la cultura, enfermedades populares de interés psiquiátrico y antropológico; el cual contiene una serie de artículos que toman especia interés sobre enfermedades propias en ciertas culturas, entre ellas el Grisi siknis.

El investigador que desarrolla el artículo es el psiquiatra, Philip A. Dennis, el cual toma especial interés en las narrativas de los muskitus respecto a los síntomas y como explicaban su malestar. A continuación presentaré algunos apuntes de su trabajo:

Como veremos, la historia del Miskito se refleja hasta cierto punto en la experiencia grisi siknis, un síndrome dramático ligado a la cultura (...), que ocurre entre los miskitus. Las víctimas de la condición, pierden el conocimiento, creen que los demonios los golpean y tienen relaciones sexuales con ellos, y corren a través del pueblo hacia el arbusto. La afección también puede implicar un comportamiento violento y agresivo, como amenazar a otros con machetes y botellas rotas. Afecta principalmente a mujeres jóvenes, y es epidémico y contagioso en su forma.

Mientras huyen de sus casas durante los ataques, las víctimas gritan y hablan con el diablo. A menudo usan inglés o español (...) (Dennis, 1985, pág. 289)

A continuación presentaré algunas narrativas recopiladas por el psiquiatra, Philip Dennis (1985, pág. 240) en su artículo, el cual deja en evidencia las experiencias vividas durante el padecer:

"Llega una persona, pierdes los sentidos. Si eres hombre, viene una mujer para ti. Si eres mujer, viene un hombre"

"Las personas, los hombres vienen por ti, se lo hacen a las mujeres [risas]. Tenemos miedo cuando otras personas nos miran y se ríen de nosotros" 


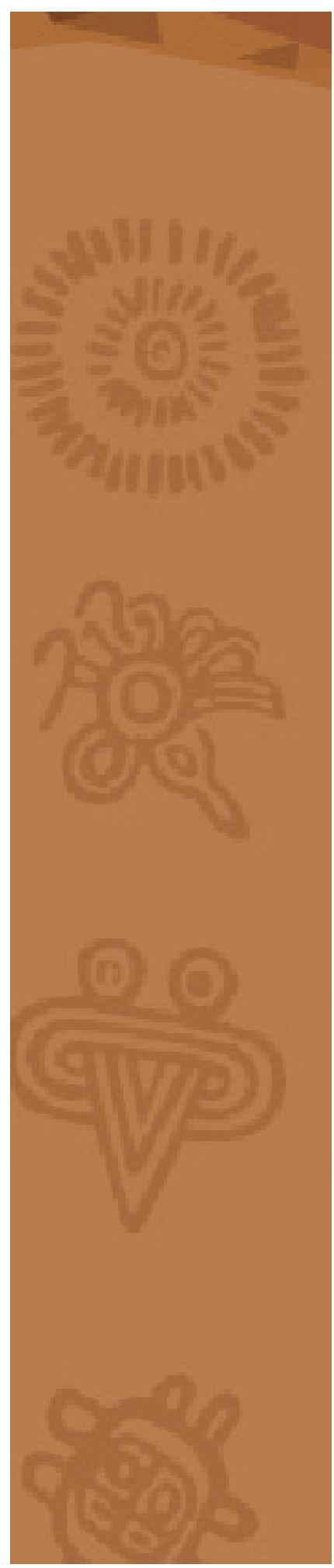

“Un hombre guapo viene de un gran barco. A él le gustaría ser tu esposo, todo para ti.

"Una mujer blanca viene a mí en un taxi y me dice: ¡¡Vamos!" Ella me lleva a un lugar, una ciudad, como Puerto Cabezas para viajar. Ella tiene sexo conmigo, pero a veces ella me corta con un cuchillo. No me gusta."

“Es un hombre guapo, quiere llevarme a su país. Él viene y se acuesta entre mi esposo y yo. “¡El machete está ahí! ¡La botella está ahí! ¡Agárralo!“, me dice.

"Algo así como un hombre viene, un hombre blanco, un español, montando a caballo. Me llevó por la playa, seis horas o más me fui y la gente no sabía dónde estaba. Me llevó a un gran salón, me dio comida y quiso bailar conmigo Era un hombre guapo, no me golpeó. Sí, lo hizo para ¡mi!

Hasta el momento no se cuenta con un estudio antropológico nacional, que analice, de forma integral, las posibles interpretaciones de las narrativas antes presentadas.

Otra enfermedad propia en Nicaragua es el Bla. En la Guía Latinoamericana de Diagnóstico Psiquiátrico (GLADP-VR, 2012, págs. 360-450) figura:

El Bla (Miskitus hondureños y nicaragüenses): referido al malestar producto del mareo durante la pesca (síntoma leve) al igual que se designa al precedente una crisis de locura (síntoma grave) los cuales presentan síntomas como: cefalea pulsátil, bilateral, dolores difusos, palpitaciones, temblores, cólera, pérdida de la conciencia, contorciones.

El manual (GLADP-VR, 2012, pág. 654) contempla la pobreza y la violencia (en especial la intrafamiliar y el machismo) como un síntoma estructural propio de las sociedades en Latinoamérica, tomando en cuenta condicionantes como el alcohol, las drogas, inseguridad y ausencia del estado en el plano comunitario.

\section{Las narrativas del malestar}

El padecer se compone de narrativas necesarias para explicar los malestares, de manera que el "diagnóstico, está ligado al conocimiento y reconocimiento de los síntomas en términos específicos que dispones el enfermo para expresar sus síntomas" (Villaseñor \& Chávez Alvarado, 2000, pág. 121) y es que en términos de expresión existen desigualdades marcadas por los estigmas y las expectativas culturales, añadido a esto, se encuentran los condicionantes sociales y estructurales.

Los Mapuches no cuentan con expresiones lingüísticas para expresar las enfermedades mentales, al menos no de forma directa; estos recurren al "Weñafkutün, un estado de pena o dolor persistente en el tiempo, siendo un concepto propio para sentirse enfermo por causas no físicas inducido por motivos externos" (Villaseñor \& Chávez Alvarado, 2000, pág. 69) 
Lo cual representa un reto complejo puesto que "los trabajadores de la salud los diagnostican bajo el cuadro de alexitimia" (Villaseñor \& Chávez Alvarado, 2000, pág. 69) es decir, la incapacidad para distinguir sus emociones y expresarlas verbalmente. Ante esta situación nos encontramos entre tensiones conceptuales marcadas entre la cultura (expresión) y la biomedicina (diagnóstico), incompatibles entre sí. Por tal razón, los autores recomiendan el uso del manual GLADP, adaptado a las sensibilidades culturales en Latinoamérica.

Desde el lenguaje, las expresiones cobran sentido. La semiótica construye los procesos sociales adecuados a la cultura del individuo, de manera que es capaz de comunicarse, y su receptor, capaz de entender el mensaje.

La antropología de la salud es capaz de coincidir la enfermedad mental desde las interpretaciones que las personas expresan a partir de sus sistemas lingüísticos y simbólicos, parte de este proceso es de suma importancia, puesto que en como percibimos las expresiones influirá en como interpretamos el síntoma y como establezcamos el diagnóstico.

Natalia Carceller-Maicas, antropóloga médica, explica:

Para entender en profundidad la enfermedad, resulta de especial interés aproximarse a los modelos explicativos de malestar empleados por las personas, sólo así lograremos entender los modos en que estos perciben, sienten y viven el sufrimiento emocional. Es necesario analizar las narrativas del padecer, rescatando los saberes subalternos, los cuales habitualmente quedan silenciados bajo la hegemonía del Modelo Biomédico" (Carceller-Maicas, 2017, págs. 270-271)

Como anteriormente se planteaba, el síntoma de una misma patología puede variar en sus expresiones del padecer según la cultura y la coyuntura del contexto que habita el enfermo/ paciente.

Se debe reflexionar sobre lo siguiente:

Las diferentes maneras de percibir, entender y vivir el malestar resultan en distintos modos de nombrarlo; y viceversa, configurando de este modo mundos vitales de palabras con cargas sintomatológicas propias del medio social y cultural con repercusión directa en el individuo (Carceller-Maicas, 2017, pág. 272)

Hay que tomar en cuenta que el malestar emocional "es un estado temporal y circunstancial ligado al mundo afectivo, que compila un variado abanico de padecerles, que pueden estar relacionados a la enfermedad o a la situación que se atraviesa" (Carceller-Maicas, 2017, pág. 271) Es decir que el padecer abarca los síntomas físicos y los somáticos, al igual que la situación por la que el enfermo/paciente atraviesa, entendiendo "el mundo de las percepciones o sentires". 


\section{La violencia como una patología social latinoamericana}

La violencia (sin negar su concepto histórico y trascendencia geográfica) toma particular evolución y desarrollo en Latinoamérica, puesto que deriva como un malestar estructural (producto de las políticas y la economía) y no biológico, sin embargo, los síntomas directos tienen, en efecto, condicionantes biológicos

En 2014, un grupo de médicos investigadores de McLean Hospital, Harvard Medical School y Northeastern University, a cargo del doctor Martin Teicher, analizaron imágenes de resonancia magnética (MRI) a más de 200 personas que en su infancia fueron víctimas de violencia intrafamiliar, y compararon los resultados con 164 personas que no fueron víctimas.

El análisis demostró que el maltrato estaba "vinculado con alteraciones en la arquitectura de la red cortical" (Teicher, Anderson, \& Ohashi, 2014, pág. 297) esta arquitectura marcaba la diferencia entre el grupo de los que habrían sido violentados de los que no en la centralidad "de nueve regiones cerebrales y en el conjunto de regiones que conforman el 'club de ricos' de la red" (Teicher, Anderson, \& Ohashi, 2014, pág. 297)

El estudio demostró las afectaciones directas en dos regiones cerebrales: la ínsula anterior derecha, la cual "participa en la integración y coordinación de la percatación subjetiva de necesidades urgentes y sentimientos internos" (Teicher, Anderson, \& Ohashi, 2014, pág. 298) y el cíngulo anterior izquierdo, el cual "participa en la regulación de emociones e impulsos" (Teicher, Anderson, \& Ohashi, 2014, pág. 298)

Otras regiones cerebrales en donde los investigadores notaron alta centralidad son las siguientes (Teicher, Anderson, \& Ohashi, 2014):

Pre-cúneo derecho, vinculado al pensamiento egocéntrico, el cual puede estar íntimamente vinculado a la construcción cultural del patriarcado como máxima exaltación e idealización de la figura dominante.

Lóbulo temporal, responsable de pensamientos ligados a las creencias Lóbulo occipital, encargado de las percepciones consientes.

La cisura y circunvolución pre-central, responsable de la coordinación motriz y las percepciones sensoriales.

Como conclusión el artículo determina que:

El maltrato infantil es un factor estresante grave que altera las trayectorias del desarrollo cerebral. Las regiones que participan en el monitoreo de la percepción o conciencia interna de las emociones se convierten en núcleos de actividad sumamente conectados y por lo tanto pueden ejercer mayor influencia en el comportamiento de una persona.

Al mismo tiempo, las regiones que controlan los impulsos pierden conexiones y quedan relegadas a una labor menos central dentro de la red. Estos cambios pueden sentar las 
bases para que haya un mayor riesgo de consumo de drogas y otros trastornos de salud mental a lo largo de la vida (Teicher, Anderson, \& Ohashi, 2014, pág. 301)

Es decir, desde las funciones neurobiológicas están demostradas las alteraciones en los comportamientos, racionalidades, impulsividades y autorregulaciones ante emociones y situaciones, pero ¿cómo vincular el determinismo biológico a los contextos socioculturales, toando en cuenta las condiciones de género, desigualdades estructurales y legados coloniales expresados a través del patriarcado y la heteronormatividad?

Para desarrollar el planteamiento anterior, hay que tomar en cuenta el trabajo del investigador y psicólogo social, James Pennebaker (1999, pág. 380) quien asegura que los estereotipos emocionales tienden a materializarse según el género, y es más recurrente que la mujer exprese los síntomas de tristeza alegría o ira mediante somatizaciones o emociones. El hombre en cambio, recurre a métodos acorde al mandato de género para expresar sus emociones. ¿Qué quiere decir esto?

Según el investigador y politólogo, Eduardo Gamarra (1988, pág. 4) los mineros en el altiplano boliviano, presentan tensiones físicas extremas e inestabilidades afectivas producto del trabajo realizado en las minas, desmotivados por los bajos salarios, se encuentras propensos a una disposición depresiva, la cual manifiestan mediante la apatía y repulsión a la vida, expresa al momento de estar bajo los efectos del alcohol. Este fenómeno es justificante del mandato masculino, siendo la excepción a la norma de ocultar el sentimiento, debido a que recurre al alcohol para encontrarse en un estado alterado de conciencia.

\section{El hambre: un patología mental propia en el Brasil neoliberal}

La antropóloga, Nancy Scheper-Hughes (1997, pág. 45) analiza la realidad en el Nor-este brasileño, entre fenómenos sociales condicionados desde el hambre, la pobreza y la violencia. Factores vinculados con la coyuntura política brasileña.

Celia Galán Arroyo (2011, pág. 26), antropóloga socio-cultural, analiza el trabajo de Scheper-Hughes, y explica que:

La medicalización del hambre a través del discurso de los nervios (nervoso) corresponde con expresiones sobre la pobreza y la consecuente falta de alimentación que sufren (problemas estructurales), sin embargo, este discurso se ve mediado a través de instituciones sanitarias que catalogan el problema como síntomas de nervios, un "trastorno psiquiátrico", susceptible de ser curados por medio de medicamentos. El hambre no se cura con pastillas, pues haría falta un cambio socio-político, mientras que los nervios, son fácilmente controlados por medio de medicamentos.

El hambre, desde el paradigma psiquiátrico neokrapeliniano, es decir, el paradigma que considera que los trastornos mentales tienen una base y origen biológica, generalmente se consideran "irregularidades" que deben ser tratadas con psicofármacos, "para restablecer su curso normal”" (Galán Arroyo, 2011, pág. 33) y desde el neoliberalismo 


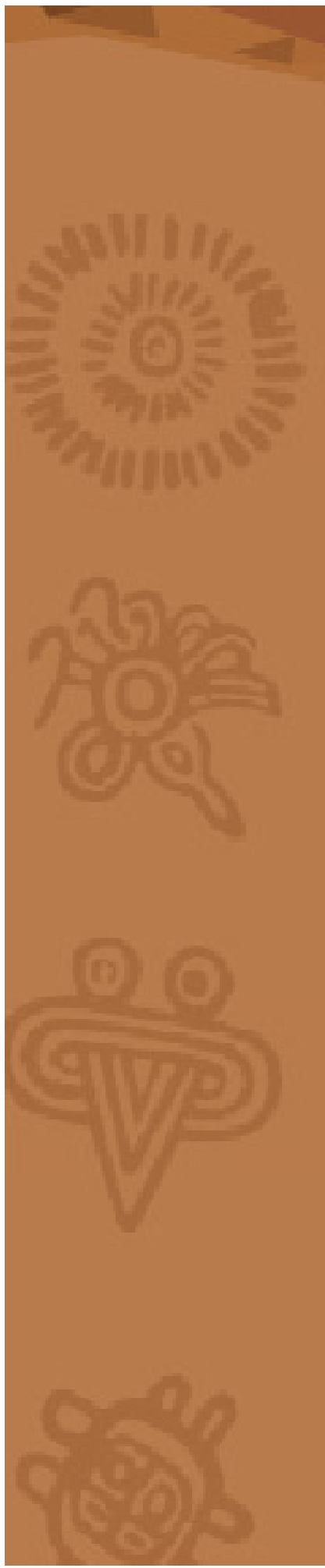

el hambre y la pobreza son síntomas irregulares necesarios de corregir por medio de la salubridad, sin embargo se acortan los mecanismos de acción política y social para corregir las verdaderas irregularidades de corte estructural que mantienen las condiciones de vida necesarias para perpetrar la pobreza, el hambre y la violencia.

La coyuntura brasileña de 1990, coincide con la nicaragüense, período de tiempo en que el neoliberalismo primó como paradigma político y social. Scheper-Hughes (1997, pág. 27) aporta a la antropología de la salud desde las perspectivas y categorías de análisis entre las estructuras políticas, los fenómenos sociales y los síntomas patológicos, este último como resultado de la suma de los dos anteriores. Sin embargo, la violencia se exterioriza contra la institución, es decir, trasciende el núcleo familiar al plano comunitario, en donde materializan su odio contra el arquetipo asumido como la raíz patológica de sus ausencias: el estado.

Por tanto la ausencia o presencia de armas no define un fenómeno como violento, si no las estructuras implícitas que actúan en contra posición, las cuales deben responder en todo momento a un orden simbólico para mantener su condición de violencia; tomando en cuenta que la violencia no implica una ruptura de la cultura, pues sirve a la misma para mantener el orden estructural y simbólico.

Es por tal razón que la violencia es el resultado entre las relaciones de poder presentes en un marco comunitario y los conflictos que han resaltado para estructurar un conflicto, apartando el análisis de la violencia como un constructo social (legitimando la violencia como algo propio del grupo o inherente al ser humano) la cual tiene alcances biológicos y relaciones socio-afectivas.

\section{Conclusiones}

Las enfermedades desde sus bases biológicas, comprenden sintomatologías específicas y generalizadas capaces de ser entendidas en cualquier contexto geográfico; sin embargo, hay que prestar especial atención a los síntomas narrados desde el padecer y el sufrir del paciente. El paciente cuenta con un entramado lingüístico y simbólico por el cual expresa su malestar, y este entramado responde a las particularidades específicas de su contexto sociocultural, las realidades históricas, políticas y las correlaciones del poder, afecto y emociones. El estado del arte cumple la función de ser una sistematización para que investigadores y servidores de la salud comprendan el impacto significativo del sentir, padecer y expresar un mal desde los recursos propios de los pacientes y como se pueden construir diálogos para encontrar "curas" adecuadas y apropiadas, en común.

\section{Bibliografía}


Carceller-Maicas, N. (2017). Mundos vitales de palabras: análisis del sufrimiento mediante narrativas del malestar. Revista Latinoamericana de Ciencias Sociales, Niñez y Juventud, 269283.

Dennis, P. (1985). Grisi Siknis in Miskito Culture. En R. Simons , \& C. Hughes, The Culture-Bound Syndromes: Folk Illnesses of Psychiatric and Anthropological Interest (págs. 289306). Berlín: Springer.

Galán Arroyo, C. (2011). La articulación y gestión del padecimiento depresivo en la cotidianeidad de los individuos . Estudios Avanzados en Antropología Social y Cultural, 3-35.

Gamarra, A. (1988). Celda, cárcel, mina: Estudio sobre la psicología del minero. Oruro: Empresa Gráfica Offset; S.R.L.

GLADP-VR. (2012). Guía Latinoamericana de Diagnóstico Psiquiátrico. Obtenido de http:// www.apalweb.org/docs/gladpvr2012.pdf

Hollweg, M. (2003). Trastornos afectivos en las culturas bolivianas: un enfoque etnopsiquiátrico transcultural. Investigaciones en Salud, 5, 5-15.

Kleinman, A. (2003). Abordaje de la depresión según las culturas. Bostom: Universidad de Harvard Press.

MINSA. (2017). Ministerio del Poder Ciudadano para la Salud. Obtenido de Mapa de la Salud : http://mapasalud.minsa.gob.ni/wp-content/uploads/2017/03/Grisi-Siknis.pdf

Pennebaker, J. (1999). Sterotypes of emotional expressivennes of northerners and southerners: a cross-cultural test of Montesquieu's hypotheses . Journal of Personality and Social Psychology , 372-380.

Pewzner-Apeloig, E. (1999). El hombre culpable: la locura y la falta en Occidente. Méxido D.F: Fondo de Cultura Económica .

Ronald C. Simons, C. C. (1985). The Culture-Bound Syndromes: Folk Illnesses of Psychiatric and Anthropological Interest. Berlín : Springer, Dordrecht.

Scheper-Hughes, N. (1997). La muerte sin llanto: violencia y vida cotidiana . Barcelona: Ariel.

Teicher, M., Anderson, C., \& Ohashi, K. e. (2014). Childhood maltreatment: altered network centrality of cingulate, precuneus, temporal pole and insula. Biological Psychiatry, 4, 297-305.

Villaseñor, S., \& Chávez Alvarado, C. (2000). De las modalidades depresivas entre los Nahuas del alto Balsas. örgano Oficial del Instituto de Psiquiatras de Lengua Española, 120-134. 


\section{Raíces}

Revista Nicaragüense de Antropología Año 5 No.9| 2021 Enero - Junio

Villaseñor, B. S. (2005). Cuadros típicos de la región. En R. Alarcón, Psiquiatría México (págs. 12-15). México D.F: Ed. El Manual Moderno.

Villaseñor, S., Rojas, C., Albarrán, A., \& Gonzáles, A. (2006). Un enfoque transcultural de la depresión. Revista de Neuro-Psiquiatría, 69, 43-50.

Luis Carlos Ariel Ruiz Chow

Antropólogo Social en la Universidad Nacional Autónoma de Nicaragua, UNANManagua. Especialista en Gestiones Colaborativas y Economía Social Solidaria por el Programa INICIA. Coordinador de Educación Emocional en la Escuela de Alfabetización del Adulto Mayor (UNAM) y miembro activo de la red de Promotoría Solidaria de Juventud Sandinista. 